\title{
Erratum to: In situ contouring technique in the treatment of thoracolumbar fractures
}

\author{
Jean-Paul Steib · Yann Philippe Charles • \\ Mourad Aoui
}

Received: 14 September 2009/Published online: 13 October 2009

(C) Springer-Verlag 2009

\section{Erratum to: Eur Spine J}

\section{DOI 10.1007/s00586-009-1119-1}

In the article, one of our previous article was incorrectly referenced. Reference No. 5 should read: Yerby SA, Ehteshami JR, McLain RF (1997) Offset laminar hooks decrease bending moments of pedicle screws during in situ contouring. Spine 22:376-381.

The online version of the original article can be found under doi:10.1007/s00586-009-1119-1.

J.-P. Steib · Y. P. Charles - M. Aoui

Department of Spine Surgery,

University Hospital of Strasbourg,

Strasbourg, France

J.-P. Steib ( $\square)$

Service de Chirurgie du Rachis,

Hôpitaux Universitaires de Strasbourg,

1, Place de 1'Hôpital, B.P. 426,

67091 Strasbourg Cedex, France

e-mail: jean-paul.steib@chru-strasbourg.fr 